\title{
Novel MOF-Derived Nickel Nitride as High-performance Bifunctional Electrocatalysts for Hydrogen Evolution and Urea \\ Oxidation
}

Shengnan $\mathrm{Hu}^{\mathrm{a}}$, Shiquan Wang ${ }^{\mathrm{a}}$, Chuanqi Feng ${ }^{\mathrm{a}}$, Huimin $\mathrm{Wu}^{\mathrm{a}, *}$, Jiujun Zhang ${ }^{\mathrm{c}}, \mathrm{He}$ $\mathrm{Mei}^{\mathrm{b}, *}$

${ }^{a}$ Hubei Collaborative Innovation Center for Advanced Organic Chemical Materials \& Ministry-of-Education Key Laboratory for the Synthesis and Application of Organic Functional Molecules, Hubei Key Laboratory of Polymer Materials, Hubei Key Laboratory of Ferro \& Piezoelectric Materials and Devices, Faculty of Physics \& Electronic Science, College of Chemistry \& Chemical Engineering, 368 Youyi Road WuChang District, Hubei University, Wuhan 430062, PR China

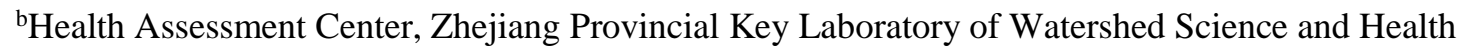
, College of Public Health and Management, University Town, Chashan, Wenzhou Medical University, Wenzhou 325035, PR China

${ }^{\mathrm{c}}$ Institute for Sustainable Energy/College of Sciences, 99 Shangda Road BaoShan District, Shanghai University, Shanghai, 200444, China

\footnotetext{
* Corresponding author
}

E-mail address: whm267@hubu.edu.cn (Huimin Wu); meihe541@163.com (He Mei)

Number of pages: 13

Number of figures: 7

Number of tables: 2

Number of references: 19 
Table of contents

1. XRD patterns of C-300 and C-400

2. SEM images of bare Ni foam, C-300, and C-400

3. LSV curves of $\mathrm{C}-350$ in $1.0 \mathrm{M} \mathrm{KOH}$ with different concentration of urea

4. Nyquist plots and $R_{c t}$ of C-300, C-350, C-400, and Pt/C

5. XRD, XPS, SEM and STEM-EDX mapping of C-350 after $3000 \mathrm{CV}$ cycles

6. CV curves of the prepared materials

7. Comparison of electrochemical performance of $\mathrm{Ni} 3 \mathrm{~N} / \mathrm{CC}$ electrolyzer in the literature

8. Comparison of catalytic performance of some UOR catalysts in recent years

9. Comparison of catalytic performance of some HER catalysts in recent years 


\section{XRD patterns of $\mathrm{C}-300$ and $\mathrm{C}-400$}

Figure S1 shows the XRD patterns of C-300 and C-400. Obviously, the diffraction peaks at $38.9^{\circ}, 42.1^{\circ}, 58.7^{\circ}, 70.3^{\circ}$ and $78.4^{\circ}$ can be indexed to (110), (002), (112), (300) and (113) lattices of $\mathrm{Ni}_{3} \mathrm{~N}$ (JCPDS No. 10-0280). In addition, the peaks at $45.1^{\circ}$, $52.1^{\circ}$ and $75.9^{\circ}$ are matched well with Ni (JCPDS No. 04-0850) and $20.2^{\circ}$ belongs to MOF.

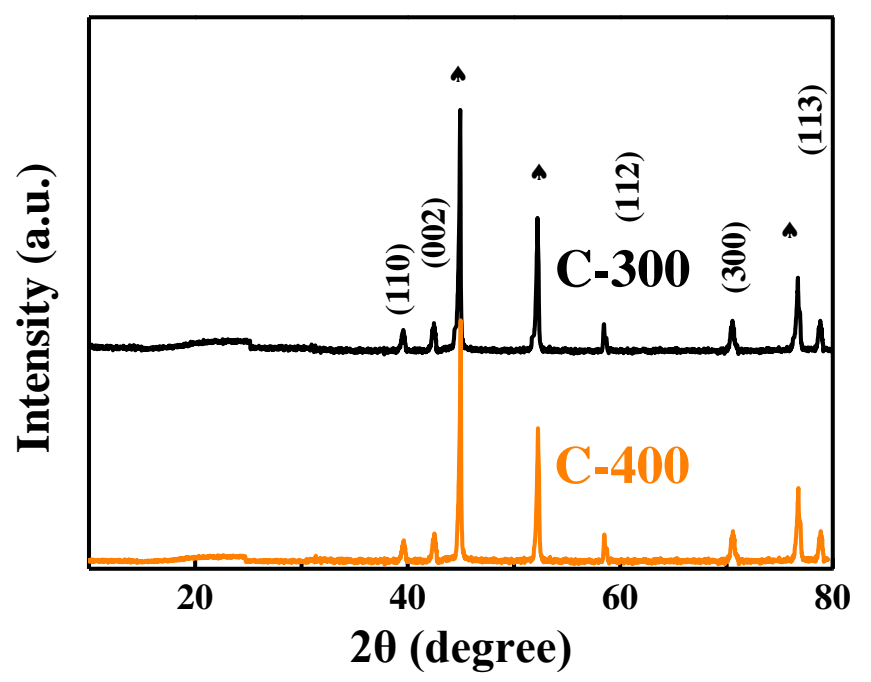

Figure S1. XRD patterns of C-300 and C-400. 


\section{SEM images of Ni foam, C-300, and C-400}

Figure S2(a) displays the SEM image of NF, indicating the surface is smooth. Figure S2(b) showed the SEM image of C-300, it is clearly the distribution of C-300 is fluffy and and retains the sheet structure. Figure S2(c) reflects the SEM image of the $\mathrm{C}-400$. We can see that the sheet structure has changed and is irregular.

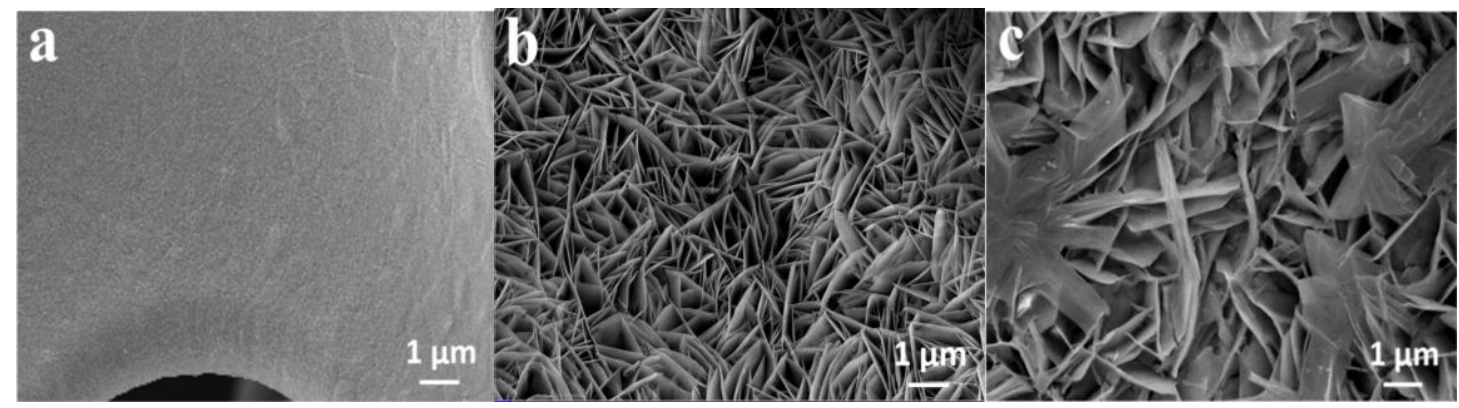

Figure S2. SEM images of (a) Ni foam, (b) C-300, and (c) C-400 


\section{LSV curves of $\mathrm{C}-350$ in $1.0 \mathrm{M} \mathrm{KOH}$ with different concentration of urea}

In order to optimize catalytic performance of UOR, we conducted the LSV of C-350 in $1.0 \mathrm{M} \mathrm{KOH}$ with different concentration of urea (from 0.1 to $0.6 \mathrm{M}$ urea). Obviously, the potential of $\mathrm{C}-350$ is the lowest in $1.0 \mathrm{M} \mathrm{KOH}$ containing $0.5 \mathrm{M}$ urea at the same current density. Therefore, the urea concentration of $0.5 \mathrm{M}$ was chosen for the electrochemical test of UOR.

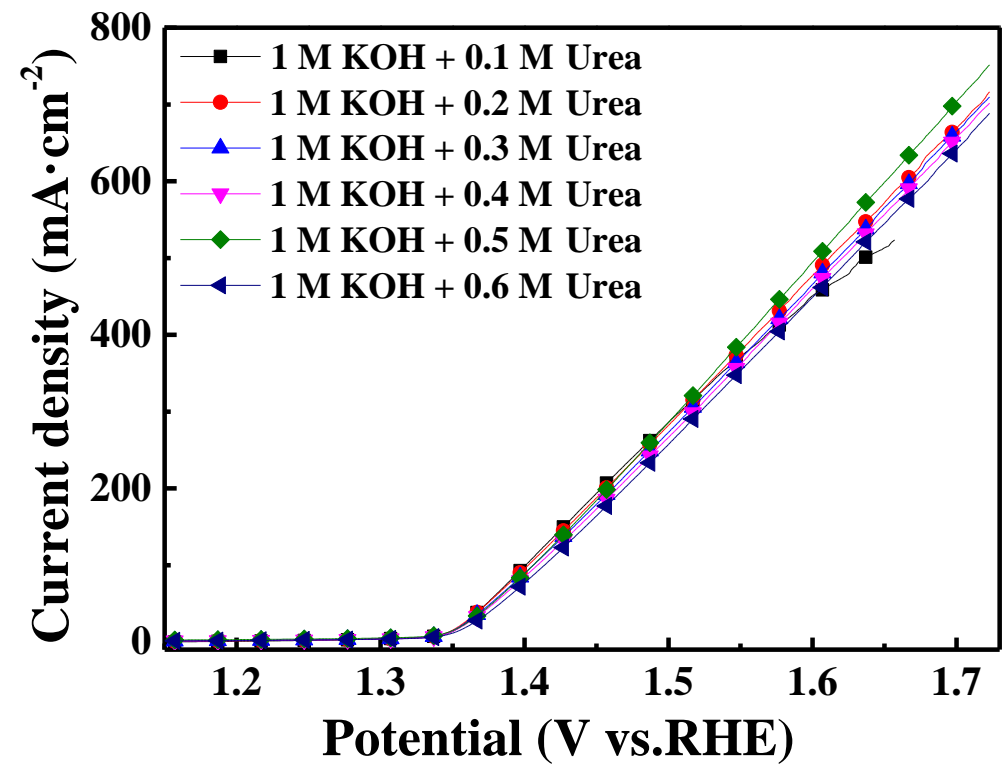

Figure S3. LSV curves of C-350 in $1.0 \mathrm{M} \mathrm{KOH}$ with $0.1,0.2,0.3,0.4,0.5$ and $0.6 \mathrm{M}$ urea, respectively. 


\section{Nyquist plots and $R_{c t}$ of C-300, C-350, C-400, and Pt/C}

Figure S4(a) shows Nyquist plots of C-300, C-350, C-400, and Pt/C in $1 \mathrm{M} \mathrm{KOH}$ with $0.5 \mathrm{M}$ urea. The $\mathrm{R}_{\mathrm{ct}}$ of C-300, C-350, C-400, and Pt/C are corresponded to 4.18 $\Omega, 3.28 \Omega, 4.41 \Omega$, and $5.81 \Omega$ (Figure $\mathbf{S 4}(\mathbf{b})$ ). Obviously, the $\mathrm{R}_{\mathrm{ct}}$ of $\mathrm{C}-350$ is the lowest. So, C-350 has faster electron transfer rate than other prepared catalysts.
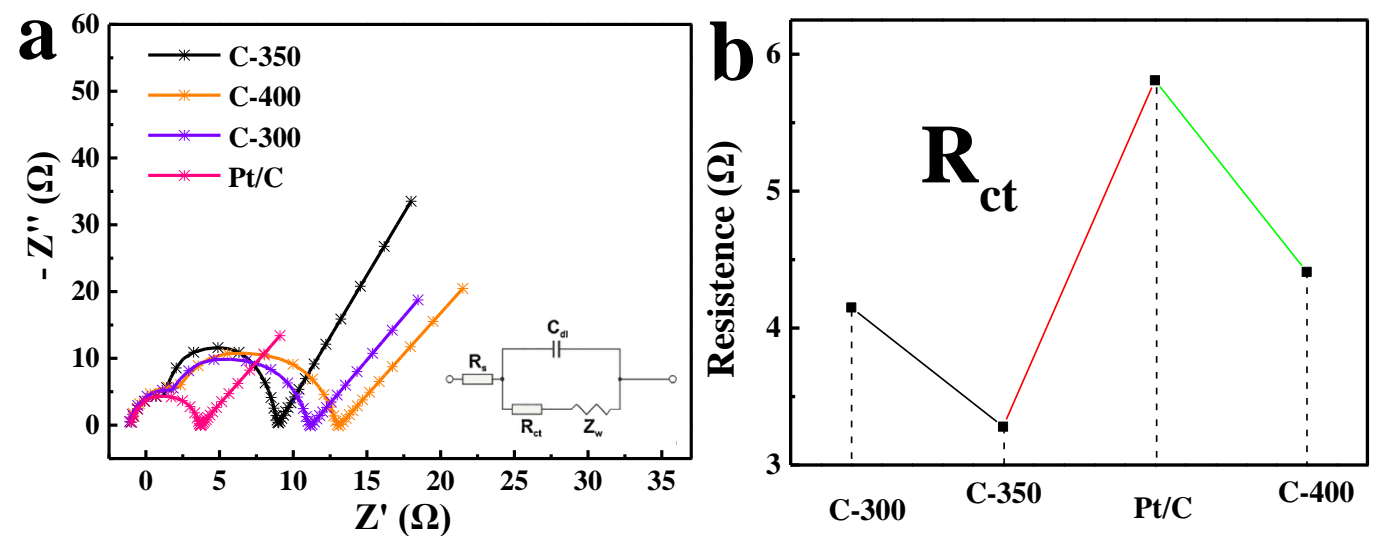

Figure S4. (a) Nyquist plots with an equivalent circuit (inset) and (b) Rct of C-300,

$$
\text { C-350, C-400, and Pt/C. }
$$




\section{XRD, XPS, SEM and STEM-EDX mappings of C-350 after $3000 \mathrm{CV}$ cycles}

Figure S5(a) shows XRD pattern of C-350 after 3000 CV cycles. Obviously, the peaks are almost the same as those before $3000 \mathrm{CV}$ cycles, matches well with the standard cards. Meanwhile, XPS spectras of Ni 2p, and N 1s for C-350 after $3000 \mathrm{CV}$ cycles are almost the same as those before $3000 \mathrm{CV}$ cycles (Figure $\mathbf{S 5}(\mathbf{b}, \mathbf{c})$. SEM images of C-350 after $3000 \mathrm{CV}$ cycles also maintain the same appearance as before 3000 CV cycles (Figure S5(d)). Figure S5(e, f) shows the STEM-EDX mapping images of C-350 after $3000 \mathrm{CV}$ cycles. The element mappings indicate that the distribution of $\mathrm{Ni}$ and $\mathrm{N}$ is consistent with those before $3000 \mathrm{CV}$ cycles. These results indicate C-350 has an excellent stability.
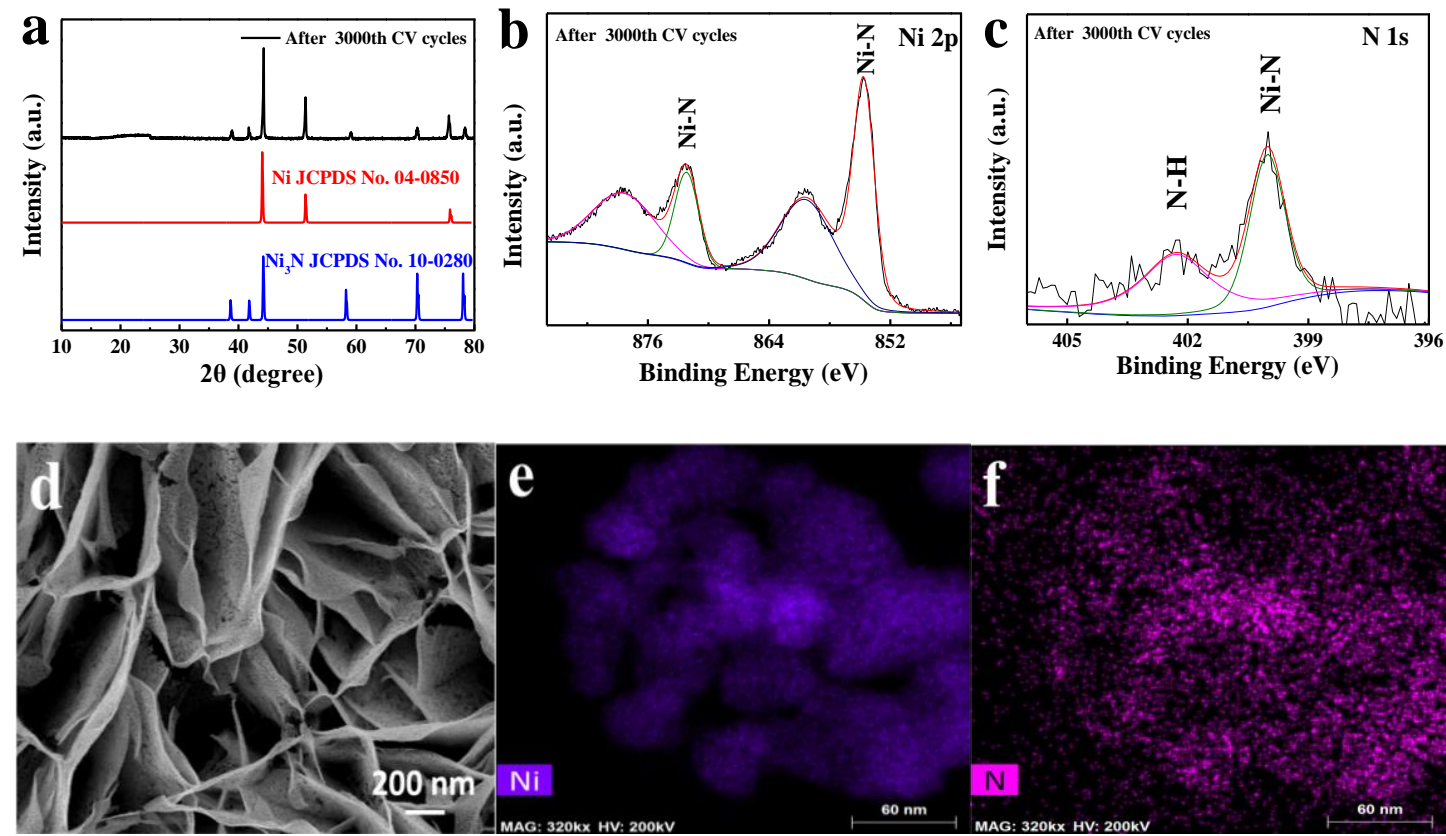

Figure S5. (a) XRD pattern, (b, c) XPS spectras, (d) SEM image and (e, f) STEM-EDX mapping of C-350 after 3000 CV cycles. 


\section{CV curves of the prepared materials}

Figure S6 shows the CV curves of (a) C-350, (b) C-400, (c) C-300, (d) Ni(OH)F, (e) $\mathrm{Ni} / \mathrm{MOF}$, and (f) $\mathrm{Ni}_{3} \mathrm{~N}$ at the scan rates from 10 to $50 \mathrm{mV} / \mathrm{s}$. The measured potential range is 0 to $0.2 \mathrm{~V}$ without obvious redox regime.
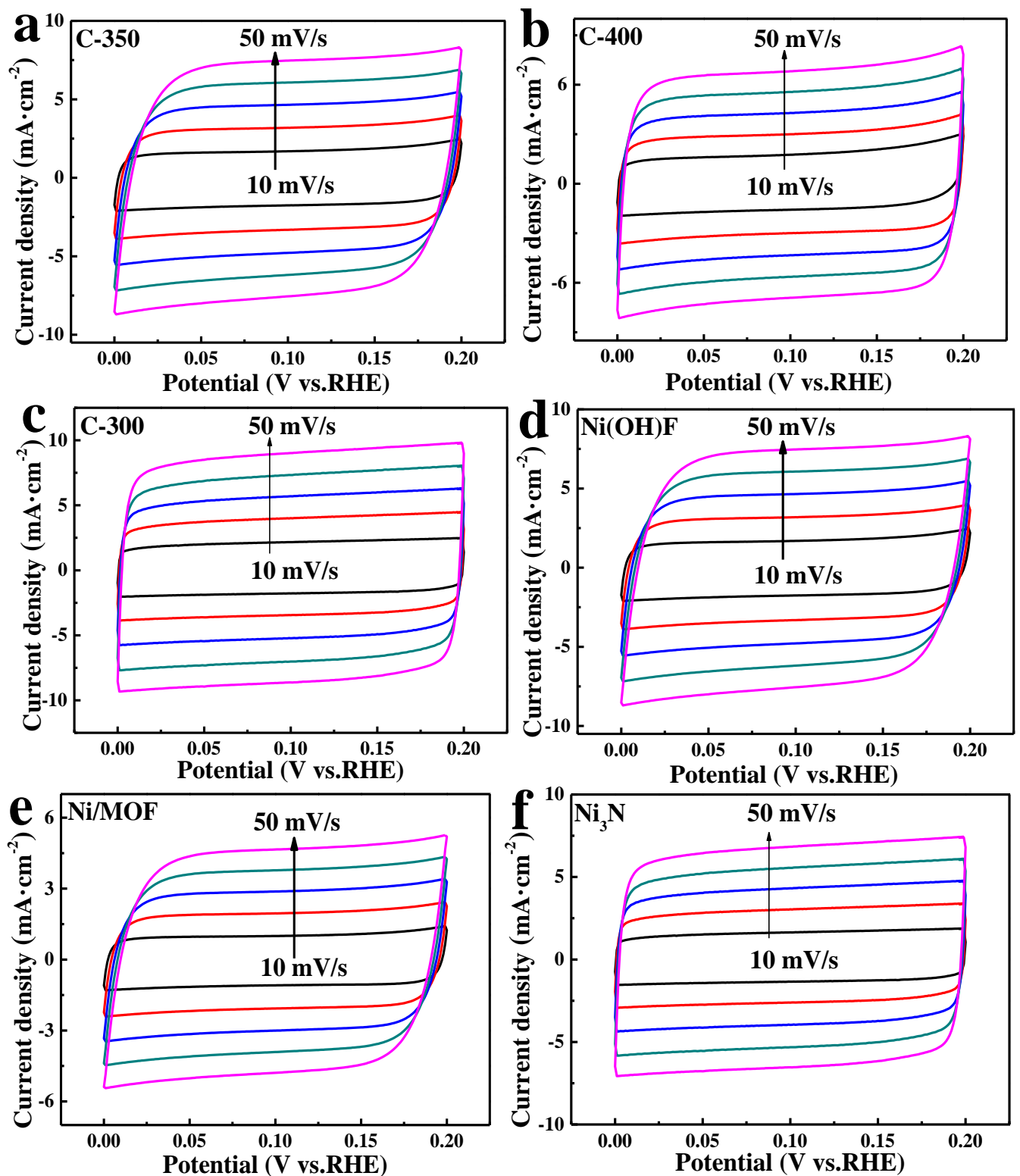

Figure S6. (a)-(f) CV curves for the prepared materials. 


\section{Comparison of electrochemical performance of $\mathrm{Ni}_{3} \mathrm{~N} / \mathrm{CC}$ electrolyzer in the}

\section{literature}

So far, only one used nickel nitride for urea electrolysis. ${ }^{1}$ The nickel nitride on carbon cloth was synthesized $\left(\mathrm{Ni}_{3} \mathrm{~N} / \mathrm{CC}\right)$ in that literature and its electrochemical performance has been compared. Obviously, the voltages of C-350 electrolyzer we prepared is much lower to that of $\mathrm{Ni}_{3} \mathrm{~N} / \mathrm{CC}$ electrolyzer. It implies the catalytic activity of C-350 electrolyzer is far superior to that of $\mathrm{Ni}_{3} \mathrm{~N} / \mathrm{CC}$ electrolyzer.

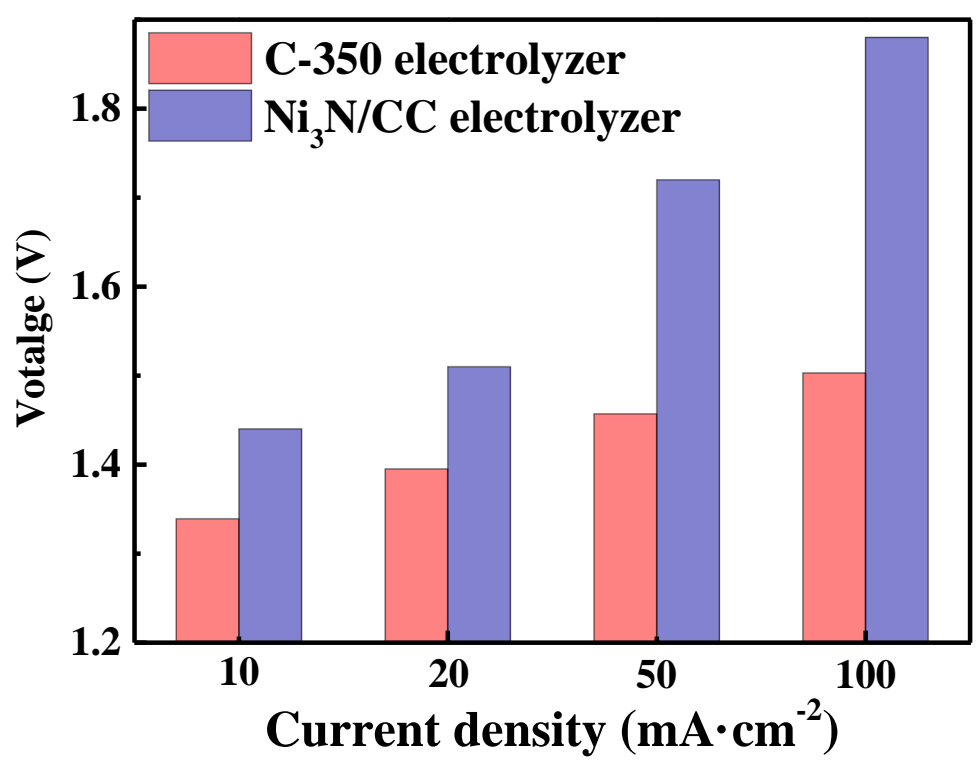

Figure S7. Histogram of $\mathrm{C}-350$ and $\mathrm{Ni}_{3} \mathrm{~N} / \mathrm{CC}$ electrolyzer. 


\section{Comparison of catalytic performance of some UOR catalysts in recent years}

Comparing the catalytic performance of catalysts for UOR in recent years.

Obviously, we can discover that the potential of the materials we prepared are lower than that of the most of UOR catalysts. This implies C-350 has superior catalytic activity and greater commercial possibilities.

Table S1. Comparison of the UOR activity for several recently reported catalysts.

\begin{tabular}{|c|c|c|c|}
\hline Catalyst & $\begin{array}{c}\text { Potential at } 10 \\
\mathrm{~mA} \cdot \mathrm{cm}^{-2}(\mathrm{~V} \text { vs} \cdot \mathrm{RHE})\end{array}$ & $\begin{array}{c}\text { Mass } \\
\operatorname{loading}\left(\mathrm{mg} \cdot \mathrm{cm}^{-2}\right)\end{array}$ & Reference \\
\hline C-350 & 1.337 & 0.35 & This work \\
\hline $\mathrm{Ni}_{3} \mathrm{~N} N A / C C$ & 1.35 & 1.9 & 1 \\
\hline $\mathrm{Ni}_{2} \mathbf{P} / \mathbf{N F}$ & 1.37 & 0.92 & 2 \\
\hline $\mathrm{Ni}(\mathrm{OH})_{2}$ nanotube-NF & 1.41 & - & 3 \\
\hline NiO nanosheet array & 1.38 & 0.27 & 4 \\
\hline Graphene $\mathrm{Ni}(\mathrm{OH})_{2}$ & 1.52 & 0.25 & 5 \\
\hline NiCo alloy & 1.53 & 10 & 6 \\
\hline NiMo sheet array & 1.37 & 0.75 & 7 \\
\hline $\mathrm{L}_{-\mathrm{MnO}_{2}}$ & 1.37 & 1.5 & 8 \\
\hline $\mathrm{Ni}(\mathrm{OH})_{2}$ nanocube & 1.55 & 0.3 & 9 \\
\hline Rhodium-Ni & 1.47 & 0.7 & 10 \\
\hline
\end{tabular}




\section{Comparison of catalytic performance of HER catalysts in recent years}

The catalytic performance of catalysts for HER in literature is compared with our catalyst, as shown in Table S2. Obviously, the electrode potential of C-350 is lower than those of other HER catalysts.

Table S2. Comparison of the HER activity for several recently reported catalysts.

\begin{tabular}{|c|c|c|c|}
\hline Catalyst & $\begin{array}{l}\text { Current density } \\
\qquad(\mathbf{j}, \mathrm{mA} \\
\left.\mathrm{cm}^{-2}\right) \text { geometrical }\end{array}$ & $\begin{array}{c}\boldsymbol{\eta} \text { at the } \\
\text { corresponding } \mathbf{j} \\
(\mathrm{mV})\end{array}$ & Reference \\
\hline C-350 & 10 & 47 & This work \\
\hline U-CNT-900 & 10 & 255 & 11 \\
\hline Co-NCNT/CCa & 10 & 180 & 12 \\
\hline $\mathrm{CoOx} / \mathrm{CN}$ & 10 & 270 & 13 \\
\hline $\mathrm{NiS}_{2} / \mathrm{CC}^{\mathrm{a}}$ & 10 & 149 & \\
\hline $\mathrm{Ni}_{3} \mathrm{~S}_{2} / \mathrm{NF}^{\mathrm{a}}$ & 10 & 123 & 14 \\
\hline $\begin{array}{c}\text { MoC }_{\mathrm{x}} \\
\text { nano-octahedrons }\end{array}$ & 10 & 150 & 15 \\
\hline $\mathrm{Ni}_{2} \mathbf{P}$ nanoparticles & 10 & 230 & 16 \\
\hline $\begin{array}{c}\qquad \mathrm{WP}_{2} \\
\text { submicroparticles }\end{array}$ & 10 & 153 & 17 \\
\hline $\mathrm{CoP} / \mathrm{CC}^{\mathrm{a}}$ & 10 & 209 & 18 \\
\hline WP NA/CC ${ }^{a}$ & 10 & 150 & 19 \\
\hline
\end{tabular}




\section{References}

1. Liu, Q.; Xie, L.; Qu, F.; Liu, Z.; Du, G.; Asiri, A. M.; Sun, X. Porous $\mathrm{Ni}_{3} \mathrm{~N}$ Nanosheets Array as a High-Performance Nonnoble-Metal Catalyst for Urea-Assisted Electrochemical Hydrogen Production. Inorg. Chem. Front. 2017, 4, 1120-1124, DOI 10.1039/C7QI00185A.

2. Liu, D.; Liu, T.; Zhang, L.; Qu, F.; Asiri, A.; Sun, X. High-Performance Urea Electrolysis Towards Less Energy-Intensive Electrochemical Hydrogen Production Using a Bifunctional Catalyst Electrode. J. Mater. Chem. A 2017, 5, 3208-3213, DOI 10.1039/C6TA11127K.

3. Ji, R.; Chan, D.; Jow, J.; Wu, M. Formation of Open-Ended Nickel Hydroxide Nanotubes on Three-Dimensional Nickel Framework for Enhanced Urea Electrolysis, Electrochem. Commun. 2013, 29, 21-24, DOI 10.1016/j.elecom.2013.01.006.

4. Wu, M.; Lin, G.; Yang, R. Hydrothermal Growth of Vertically-Aligned Ordered Mesoporous Nickel Oxide Nanosheets on Three-Dimensional Nickel Framework for Electrocatalytic Oxidation of Urea in Alkaline Medium. J. Power Sources 2014, 272, 711-718, DOI 10.1016/j.jpowsour.2014.09.009.

5. Wang, D.; Yan, W.; Vijapur, S.; Bottte, G. Electrochemically Reduced Graphene Oxide-Nickel Nanocomposites for Urea Electrolysis. Electrochim. Acta 2013, 89, 732-736, DOI 10.1016/j.electacta.2012.11.046.

6. Xu, W.; Zhang, H.; Li, G.; Wu, Z. Nickel-Cobalt Bimetallic Anode Catalysts for Direct Urea Fuel Cell. Sci. Rep. 2014, 4, 58-63, DOI 10.1038/srep05863.

7. Liang, Y.; Lin, Q.; Asiri, A.; Sun, X. Enhanced Electrooxidation of Urea Using NiMoO4 $-\mathrm{xH}_{2} \mathrm{O}$ Nanosheet Arrays on Ni Foam as Anode. Electrochim. Acta 2015, 153, 456-460, DOI 10.1016/j.electacta.2014.11.193.

8. Chen, S.; Duan, J.; Vasileff, A.; Qiao, S. Size Fractionation of Two-Dimensional 
Sub-Nanometer Thin Manganese Dioxide Crystals towards Superior Urea Electrocatalytic Conversion. Angew. Chem. Int. Ed. 2016, 128, 3868-3872, DOI 10.1002/anie.201600387.

9. Wu, M.; Ji, R.; Zheng, Y. Nickel Hydroxide Electrode with a Monolayer of Nanocup Arrays as an Effective Electrocatalyst for Enhanced Electrolysis of Urea. Electrochim. Acta 2014, 144, 194-199, DOI 10.1016/j.electacta.2014.08.098.

10. Miller, A.; Hassler, B.; Botte, G. Rhodium Electrodeposition on Nickel Electrodes Used for Urea Electrolysis. J. Appl. Electrochem. 2012, 42, 925-934, DOI 10.1007/s10800-012-0478-1.

11. Gao, S.; Li, G.; Liu, Y.; Chen, H.; Feng, L.; Wang, Y.; Yang, M.; Wang, D.; Wang, S.; Zou, X. Electrocatalytic $\mathrm{H}_{2}$ Production from Seawater Over Co, N-Codoped Nanocarbons. Nanoscale 2015, 7, 2306-2316, DOI 10.1039/C4NR04924A.

12. Xing, Z.; Liu, Q.; Xing, W.; Asiri, A. M.; Sun, X. Interconnected Co-Entrapped, N-Doped Carbon Nanotube Film as Active Hydrogen Evolution Cathode over the Whole pH Range. ChemSusChem 2015, 8, 1850-1855, DOI 10.1002/cssc.201500138. 13. Jin, H.; Wang, J.; Su, D.; Wei, Z.; Pang Z.; Wang, Y. In Situ Cobalt-Cobalt Oxide/N-Doped Carbon Hybrids as Superior Bifunctional Electrocatalysts for Hydrogen and Oxygen Evolution. J. Am. Chem. Soc. 2015, 137, 2688-2694, DOI 10.1021/jacs.7b12861.

14. Tang, C.; Pu, Z.; Liu, Q.; Asiri, A. M.; Sun, X. NiS 2 Nanosheets Array Grown on Carbon Cloth as an Efficient 3D Hydrogen Evolution Cathode. Electrochim. Acta 2015, 153, 508-514, DOI 10.1016/j.electacta.2014.12.043.

15. Wu, H.; Xia, B.; Yu, L.; Yu, X.; Lou, X. Porous Molybdenum Carbide Nano-Octahedrons Synthesized Via Confined Carburization in Metal-Organic Frameworks for Efficient Hydrogen Production. Nat. Commun. 2015, 6, 6512, DOI 
10.1038/ncomms7512.

16. Feng, L. Vrubel, H. Bensimon, M. Hu, X. Easily-Prepared Dinickel Phosphide $\left(\mathrm{Ni}_{2} \mathrm{P}\right)$ Nanoparticles as an Efficient and Robust Electrocatalyst for Hydrogen Evolution. Phys. Chem. Chem. Phys. 2014, 16, 5917-5921, DOI 10.1039/c4cp00482e.

17. Xing, Z.; Liu, Q.; Asiri, A. M.; Sun, X. High-Efficiency Electrochemical Hydrogen Evolution Catalyzed by Tungsten Phosphide Submicroparticles. ACS Catal. 2015, 5, 145-149, DOI 10.1021/cs5014943.

18. Tian, J. Liu, Q. Asiri, A. M. Sun, X. Self-Supported Nanoporous Cobalt Phosphide Nanowire Arrays: An Efficient 3D Hydrogen-Evolving Cathode over the Wide Range of $\mathrm{pH}$ 0-14. J. Am. Chem. Soc. 2014, 136, 7587-7590, DOI 10.1021/ja503372r.

19. Pu, Z. Liu, Q. Asiri, A. M. Sun, X. Tungsten Phosphide Nanorod Arrays Directly Grown on Carbon Cloth: A Highly Efficient and Stable Hydrogen Evolution Cathode at All pH Values. ACS Appl. Mater. Inter. 2014, 6, 21874-21879, DOI 10.1021/am5060178. 